\title{
Groin flap for salvage of upper extremity following necrotizing fasciitis: A case report
}

\author{
Chenicheri Balakrishnan MD, Venkata S Erella MD, Shawn Vandemark MD, Jason Mussman BA
}

C Balakrishnan, VS Erella, S Vandemark, J Mussman. Groin flap for salvage of upper extremity following necrotizing fasciitis: A case report. Can J Plast Surg 2005;13(3):153-155.

Necrotizing soft tissue infections are often associated with significant morbidity and mortality. Early surgical excision along with antibiotic therapy is the cornerstone of management. Salvage of these extremities is often difficult due to loss of soft tissues, tendons, nerves and blood vessels. Skin grafting of the granulating wound is the common method of closure in these patients. Use of various flaps has improved reconstructive options in these extremities. A case of salvage of upper extremity using a groin flap following extensive debridement is reported.

Key Words: Necrotizing fasciitis

\section{Un lambeau de l'aine pour sauver une extrémité supérieure après une fasciite nécrosante : Un rapport de cas}

\begin{abstract}
Les infections nécrosantes des tissus mous s'associent souvent à une morbidité et une mortalité considérables. Une excision chirurgicale précoce accompagnée d'une antibiothérapie constitue la pierre angulaire de la prise en charge. Il est souvent difficile de sauver ces extrémités en raison de la perte des tissus mous, des tendons, des nerfs et des vaisseaux sanguins. Une greffe cutanée de la lésion granulaire constitue la principale méthode de fermeture chez ces patients. L'utilisation de divers lambeaux améliore les possibilités de reconstruction de ces extrémités. Un cas de sauvetage d'une extrémité supérieure à l'aide d'un lambeau de l'aine par suite d'un débridement important est exposé.
\end{abstract}

Tulminating soft tissue infection of the upper extremity is

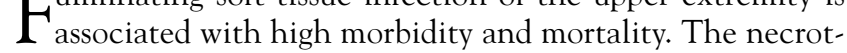
ic and gangrenous area may require wide excision, including the fascia at the depth of the wounds. Occasionally, amputation may be necessary and even this may not halt the progression of gangrene. Although various classifications categorize these infections, they do not seem to reflect subsequent therapy and outcome. Awaiting bacterial identification could lead to delay in treatment and, in some instances, the cultures may be sterile (1).

Reconstruction of large soft tissue defects of the upper extremity following excision for necrotizing fasciitis is a challenging problem. Following debridement, regular dressing and split-thickness skin grafts are commonly used to cover these defects. Unfortunately, tendon grafts and transfers require better soft tissue coverage. Local flaps may not be available due to extent of the infection. Free tissue transfer may be possible if there are adequate recipient vessels. In patients with venous occlusion from repeated abuse, a pedicled flap may be the best option for adequate soft tissue coverage where staged tendon reconstruction is required.

\section{CASE PRESENTATION}

A 45-year-old man presented to the emergency department with pain and swelling of the right upper extremity. Although he denied using illicit drugs, he later admitted to injecting drugs into his wrist five days before presentation. His past medical history was significant for recurrent pancreatitis, anemia, insulin-dependent diabetes mellitus and congestive cardiac failure. He was left-handed. On examination, his right upper extremity was swollen with necrotic skin and blisters at the

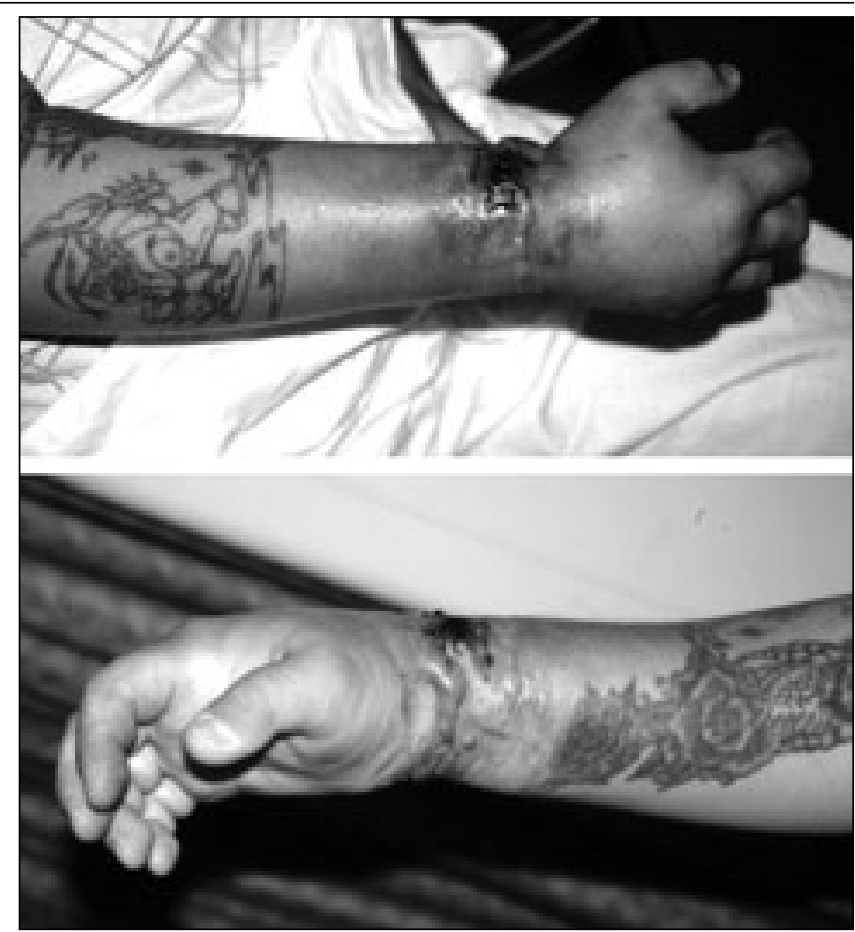

Figure 1) Necrotizing fasciitis of the wrist

wrist (Figure 1). He was febrile and had a high leukocyte count. His blood sugar was elevated secondary to sepsis. He was started on broad-spectrum antibiotics and underwent debridement of the wound. He received hyperbaric oxygen 


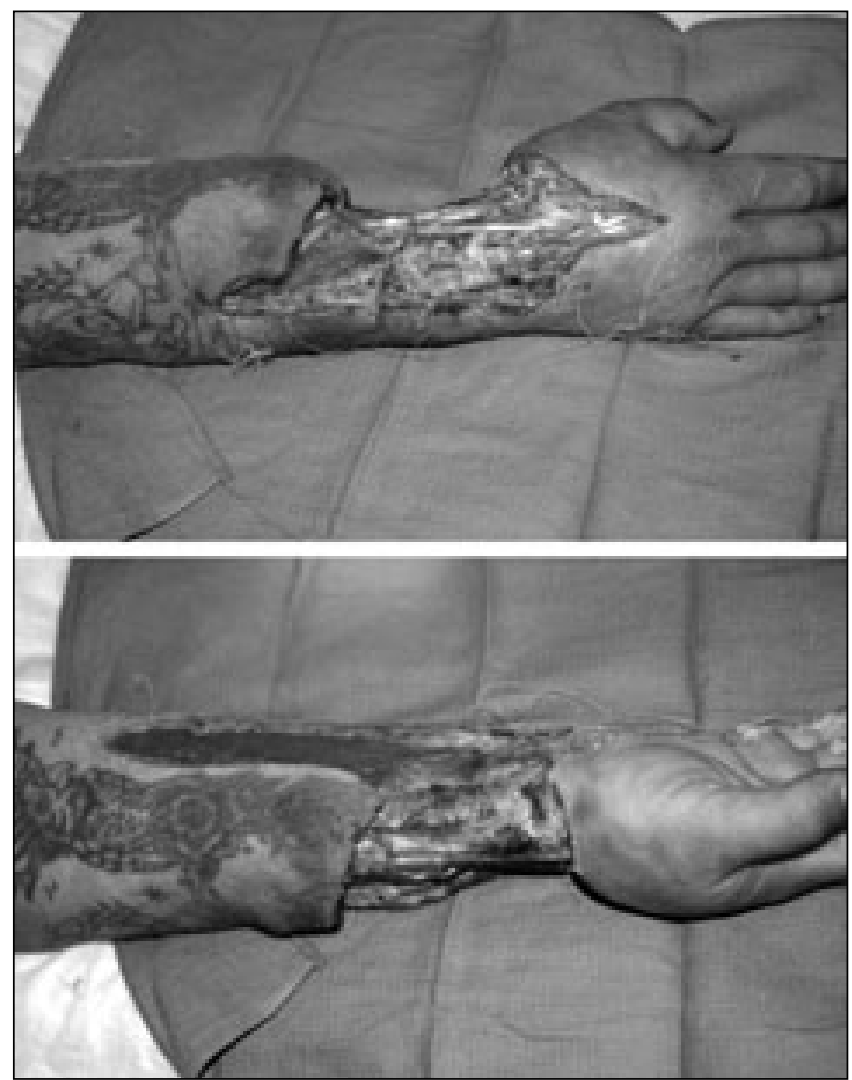

Figure 2) The fifth day following debridement

following debridement. He went back to the operating room for further debridement including extensor tendon and radial artery the following day. His leukocyte count returned to normal and blood sugars were controlled with insulin. His hand was swollen and on the fifth day still showed necrotic tissue (Figure 2). Because he wanted to save his extremity, further debridement and coverage of the defect using a groin flap were carried out (Figure 3). He was discharged home and returned three weeks later for division of the flap. The extremity has healed well but the patient lacks extension of the thumb and index fingers.

\section{DISCUSSION}

Necrotizing fasciitis usually occurs after perforating trauma that involves the fascia. The disease progresses with pain, edema and discolouration of the skin with or without bulla formation. These areas become gangrenous and spread rapidly and centrifugally. Systemic signs develop and may progress to overwhelming sepsis with pyrexia, tachycardia and anxiety, leading to septic shock. Disseminated intravascular coagulopathy and interstitial myositis may be present. Gangrene develops from vasculitis due to bacterial toxins. These infections frequently occur in immunocompromised individuals with diabetes, and individuals with a history of alcohol or intravenous drug abuse. The relatively benign appearance of the extremity is misleading and often results in a delay in diagnosis and increased mortality in these patients. The mortality of these infections has been reported to be lower for extremities. The diagnosis of necrotizing fasciitis is usually made clinically. Accepted treatment is
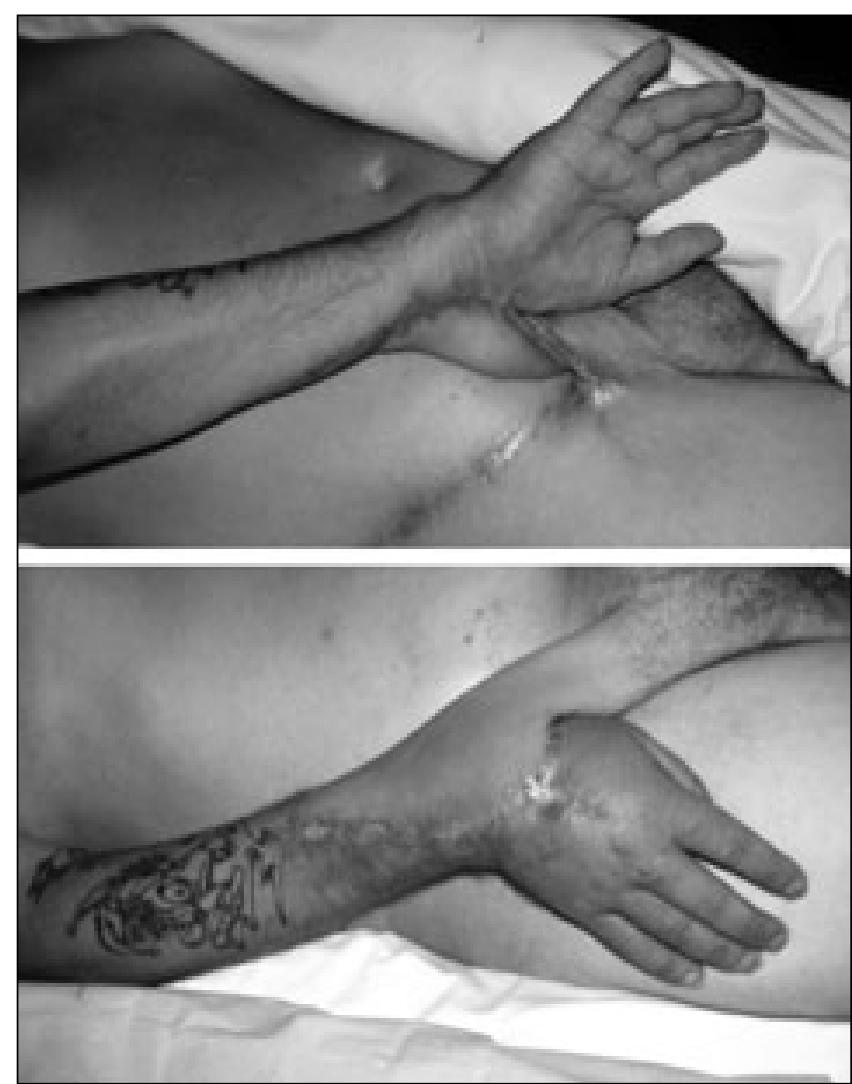

Figure 3) Pedicled groin flap covering the defect

wide excision including necrotic fascia and muscle, and leaving the wound packed open. A delay in treatment can lead to hemolysis, renal failure and death. Infection is usually polymicrobial $(1,2)$, but awaiting bacterial identification could lead to delay in treatment and, in some instances, the culture may be sterile (3). Aggressive antibiotic therapy, surgical intervention and support of vital organs offer the only chance of survival in severe cases. Occasionally, amputation may be necessary, which even may not halt progression of the gangrene. Hyperbaric oxygen has been used as an adjuvant to surgical treatment (4); to preserve the function of the extremity, use of free muscle flap with hyperbaric oxygen has been reported (5).

Studies carried out on angiosomes have helped to design flaps based on their blood supply. The groin flap (6) is an axial pattern flap based on the superficial circumflex iliac artery and the superficial venous network of the groin area. The superficial circumflex artery commonly arises from the femoral artery and, in approximately $50 \%$ of cases, there is a common trunk with the superficial epigastric artery. The point of origin lies approximately $3 \mathrm{~cm}$ below the midinguinal point. The network of vessels between the external iliac and the subclavian systems allows for expanded cutaneous surface area for the groin flap. The venous drainage is mainly into the saphenous system. The donor site can be closed primarily or skin grafted. The groin flap is usually bulky and may require revision. Although this is a staged procedure and there will be dependent edema of the hand during the pedicle stage, the groin flap is a useful alternate when free tissue transfer is not feasible. 
The present patient underwent surgical debridement of the wrist and forearm including his radial artery, flexor carpi radialis tendon, extensor policis brevis, abductor policis longus, extensor carpi radialis and extensor pollicis longus. To salvage the function of the extremity, he will require tendon reconstruction either as transfers or grafts. A large groin flap was designed to cover the defect to enable this at a later date. Being a pedicled flap, complications associated with venous circulation can be avoided in a drug abuser. Tendon reconstruction can be carried out in stages after good soft tissue coverage is obtained. The present case demonstrates the versatility of the groin flap and, in patients who require extensive debridement of hand and wrist, the groin flap can be used to salvage the extremity.

\section{REFERENCES}

1. Gonzalez MH. Necrotizing fasciitis and gangrene of the upper extremity. Hand Clin 1998;14:635-45.

2. Pessa ME, Howard RJ. Necrotizing fasciitis. Surg Gynecol Obstet 1985;161:357-61.

3. Freischlag JA, Ajalat G, Busuttil RW. Treatment of necrotizing soft tissue infections. The need for a new approach. Am J Surg 1985;149:751-5.

4. Topper SM, Plaga BR, Burner WL III. Necrotizing myonecrosis and polymicrobial sepsis. The role of adjunctive hyperbaric oxygen. Orthop Rev 1990;19:895-900.

5. Yuen JC, Feng Z. Salvage of limb and function in necrotizing fasciitis of the hand: Role of hyperbaric oxygen treatment and free muscle flap coverage. South Med J 2002;95:255-7.

6. McGregor IA, Jackson IT. The groin flap. Br J Plast Surg 1972;25:3-16 